www.jmscr.igmpublication.org

Impact Factor 5.84

Index Copernicus Value: 83.27

ISSN (e)-2347-176x ISSN (p) 2455-0450

crossref DOI: https://dx.doi.org/10.18535/jmscr/v5i2.35

\begin{abstract}
Journal Of Medical Science And Clinical Research
IGM Publication

An official Publication of IGM Publication
\end{abstract}

\title{
FNAC Vs Histopathology in the Diagnosis of Thyroid Swellings
}

\author{
Authors \\ Senthil Kumar ${ }^{1}$, Usha ${ }^{2}$, Manivel Ganesan ${ }^{3}$ \\ ${ }^{1}$ Associate Professor, Dept of General Surgery, Kanyakumari Govt Medical College, Kanyakumari \\ ${ }^{2}$ HOD \& Professor, Dept of General Surgery, Kanyakumari Government Medical College, Kanyakumari \\ ${ }^{3}$ Intern, Department of General Surgery, Kanyakumari Govt Medical College, Kanyakumari \\ Corresponding Author \\ Manivel Ganesan \\ Intern, Department Of General Surgery \\ Kanyakumari Government Medical College, Kanyakumari INDIA
}

\begin{abstract}
Background: Fine Needle Aspiration Cytology (FNAC) is important for pre-operative and pre-treatment diagnosis of benign and malignant thyroid lesions, thus decreasing the incidence of unwanted surgeries. FNAC of thyroid swellings is a simple, rapid, patient friendly and inexpensive procedure, which can be repeated in cases of inadequate samples. It has the best predictive value of all currently available diagnostic procedures. Bloch et al had done a comparison study between FNAC and histopathology and then found that the accuracy and FNAC was $91.6 \%{ }^{1}$. Handa et al have a similar study in which FNAC revealed a sensitivity of 97\%, specificity 100\%, a Positive Predictive Value of $96 \%$ and a negative predictive value of $100 \%$.

Materials and Methods: The present study is a prospective study and was conducted on 100 patients in the Department of General surgery, Kanyakumari Government Medical college from January2016 to December 2016. Various neck swellings presented to General Surgery department, were examined clinically after thorough history taking. They were subjected to FNAC and only those thyroid swelling cases admitted to indoor and subsequently underwent surgery were included in this study. After HP study they were compared with preoperative FNAC report. In all 100 cases, informed consent was taken prior to the surgery.

Results: Out of total 100 cases studied, 96 Cases were females \& 4 cases were males. 53 patients (53\%) had colloid goitre, 8 patients (8\%) were suspicious for follicular neoplasms, 15 patients (15\%) had Hashimotos and 11patients (11\%) had Papillary carcinoma, 10(10\%) were Atypia of undetermined significance and inadequate. Cyto-histopathological correlation of 100 cases was done. Sensitivity and specificity of the study for colloid goiter. Hashimotos, papillary carcinomas \& malignant neoplasm were $100 \%, 86.7 \% \%$ and $81.8 \%, 66.67 \%$ respectively.

Conclusion: FNAC is a safe, simple, highly accurate, economical and universally accepted modality for evaluation of thyroid lesions. FNAC helps in avoiding unwanted surgeries in patients diagnosed to have a benign pathology based on cytology. Those that are grouped in the suspicious or indeterminate category on cytology include lesions of uncertainty that are finally confirmed on histopathology. However, histopathological analysis is still remaining essential to distinguish follicular adenoma from follicular carcinoma.
\end{abstract}




\section{Introduction}

Among the endocrine organs, thyroid gland disorders are the most commonest in clinical practice. Fine-needle aspiration cytology (FNAC) plays a vital role in the evaluating patients with thyroid swellings. The vast majority of thyroid swellings are non-neoplastic lesions and only < $5 \%$ are malignant. Clinical features alone cannot distinguish between benign and malignant swellings. Thyroid cytology not only provides a definite diagnosis of malignancy but also the tumour type, thus enabling appropriate therapeutic surgery. Benign lesions can be managed conventionally. However, the incidence of thyroid malignancy is quite low and only 1 in 20 clinically identified swellings turn out to be malignant, thyroid FNAC helps in reducing the rate of surgery for benign thyroid diseases.

\section{Aims \& Objectives}

To study the sensitivity and specificity of FNAC in palpable thyroid lesions with their histopathological correlation.

\section{Material And Methods}

The present study was a prospective and interventional type of study, the study was undertaken to study the cytology of the palpable thyroid lesions and compared them with histopathology to determine its diagnostic accuracy. All the patients were clinically examined in detail and a careful palpation of the thyroid gland were done to judge precisely the location for aspiration. After brief explanation about the procedure to the patient, aspiration was done with the patient in supine or sitting position with extended neck, so as to make the thyroid swelling appear prominent. The material was obtained by using a $2.5 \mathrm{~cm}$ long, 23-25 gauge needle attached to a $10 \mathrm{cc}$ disposable syringe by applying mild suction. Multiple smears were prepared and equally divided into air dried and wet fixed smears. Wet fixed smears were immediately fixed in methanol taking precaution that the smears did not get air dried. These smears after fixation were stained with Hematoxylin and Eosin. The smears intended for Giemsa stain were quickly air dried and fixed with methanol and stained with Giemsa stain.

The cases were followed by cytology and histopathological reports received from the department of Pathology. Cytological diagnosis was correlated with histopathological diagnosis. Thus, the diagnostic accuracy, sensitivity and specificity, positive predictive value (PPV) and negative predictive value (NPV) of FNAC in diagnosing thyroid swellings were calculated.

\section{Observation \& Results}

Distribution of individual thyroid lesions based on cytological study

\section{LESIONS No of cases positive FNAC}

$\begin{array}{lcc}\text { - } \text { Colloid goiter } & 53 & 53 \\ \text { - Follicular lesions } & 08 & 08 \\ \text { - Hashimoto's } & 15 & 13 \\ \text { - Papillary carcinoma } & 11 & 09 \\ \text { - Malignant neoplasms } & 03 & 02 \\ \text { - others } & 10 & \\ \text { - Total } & 100 & \end{array}$




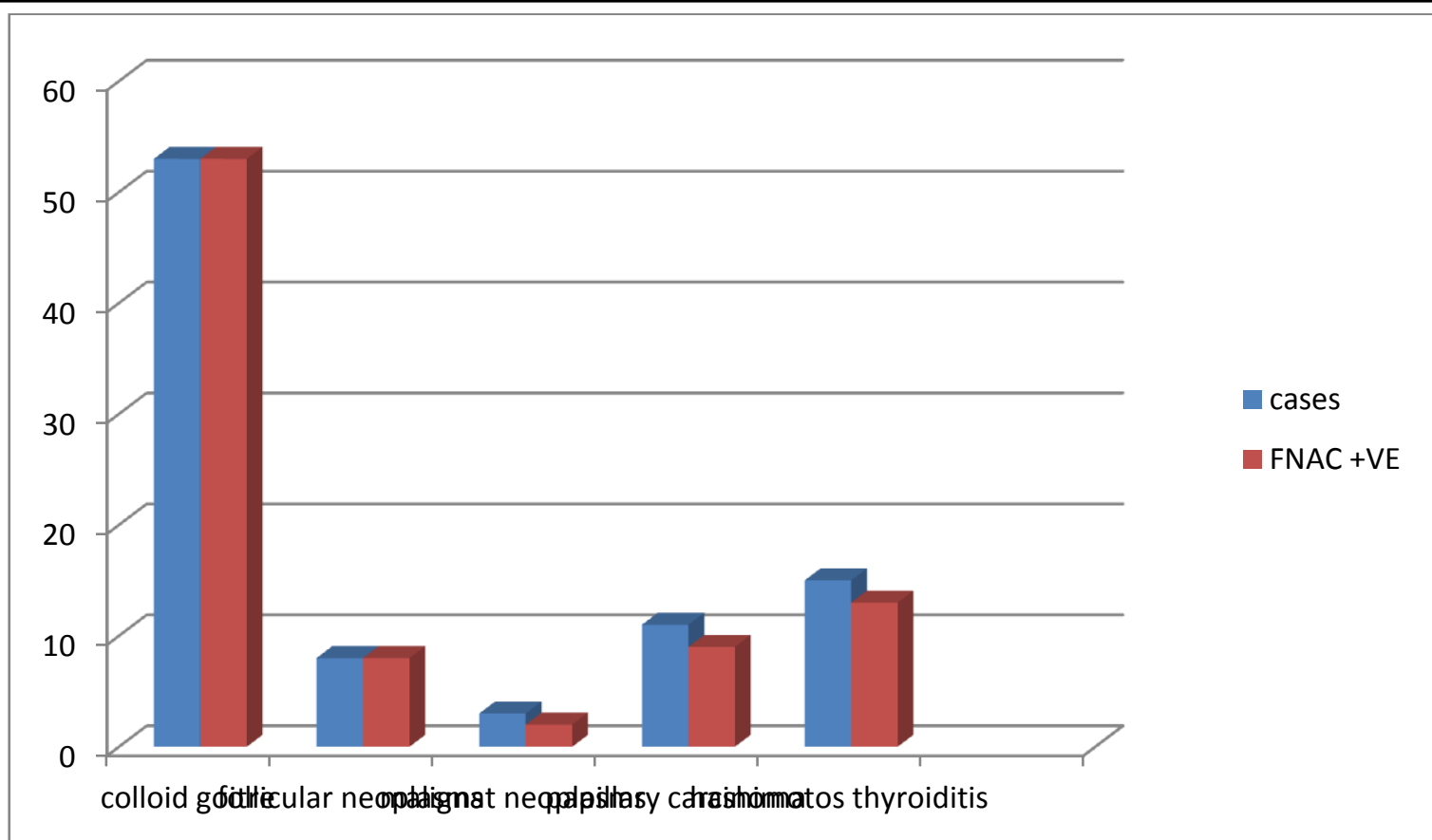

Among the 100 cases, 53 patients were diagnosed with colloid goiter and all 53 patients were positively co-related with their FNAC findings pre-operatively. Among 53 patients, 52 were females, 1 was male.

Age and sex distribution of the patients with colloid goiter:

$\begin{array}{cccc}\text { Age group (years) } & \text { Male } & \text { Female } & \text { Total } \\ 11-20 & 0 & 1 & 01 \\ 21-30 & 0 & 12 & 12 \\ 31-40 & 0 & 13 & 13 \\ 41-50 & 0 & 10 & 10 \\ 51-60 & 1 & 14 & 15 \\ >60 & 0 & 2 & 02\end{array}$

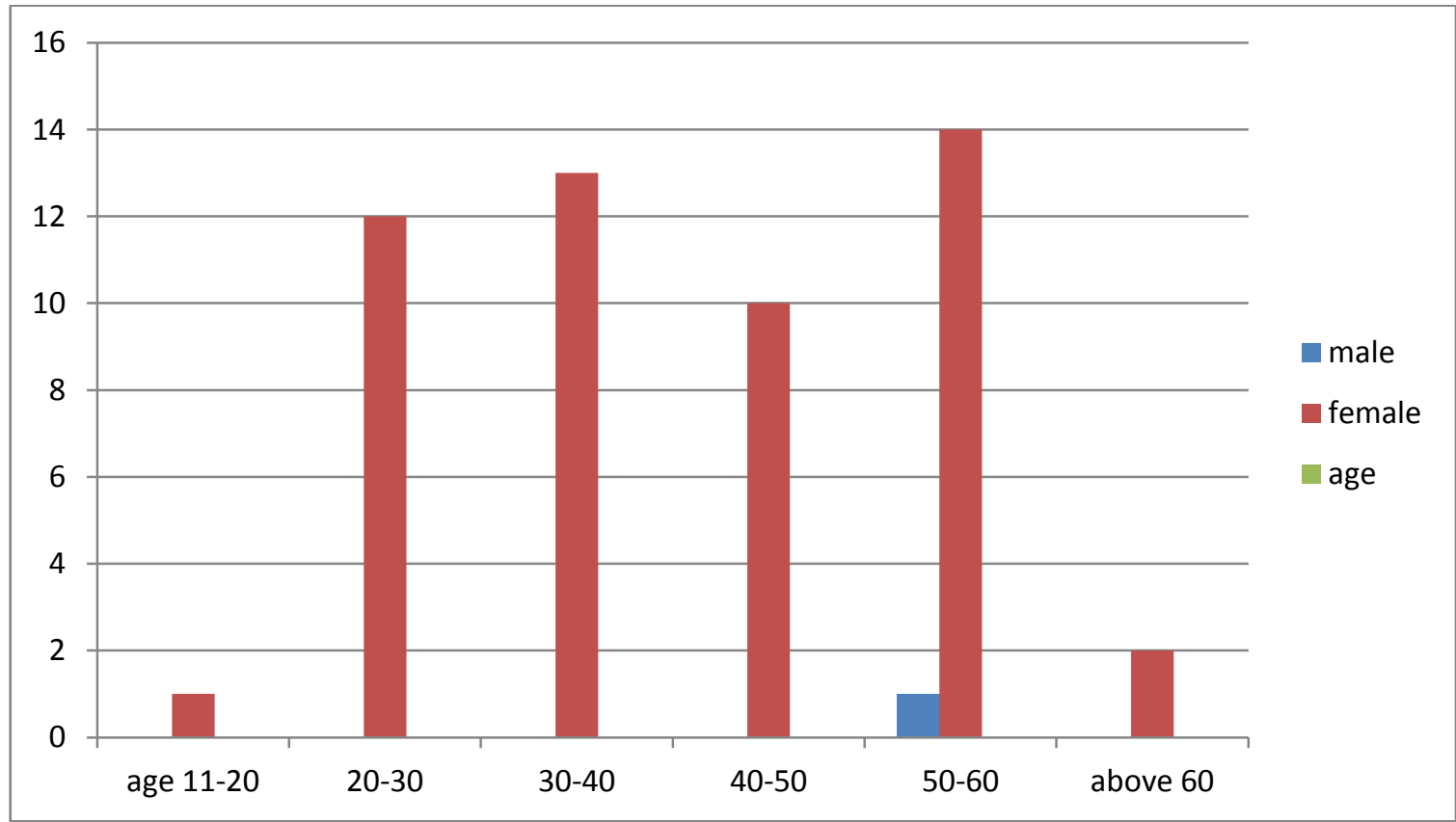




\section{JMSCR Vol||05||Issue||02||Pages 17425-17431||February}

Age and sex distribution of the patients with FOLLICULAR ADENOMA. (FNAC - Follicular Neoplasm) Age group (years) Male Female Total

$\begin{array}{llll}11-20 & 0 & 0 & 00 \\ 21-30 & 0 & 1 & 01 \\ 31-40 & 0 & 1 & 01 \\ 41-50 & 0 & 3 & 03 \\ 51-60 & 0 & 3 & 03 \\ >60 & 0 & 0 & 00\end{array}$

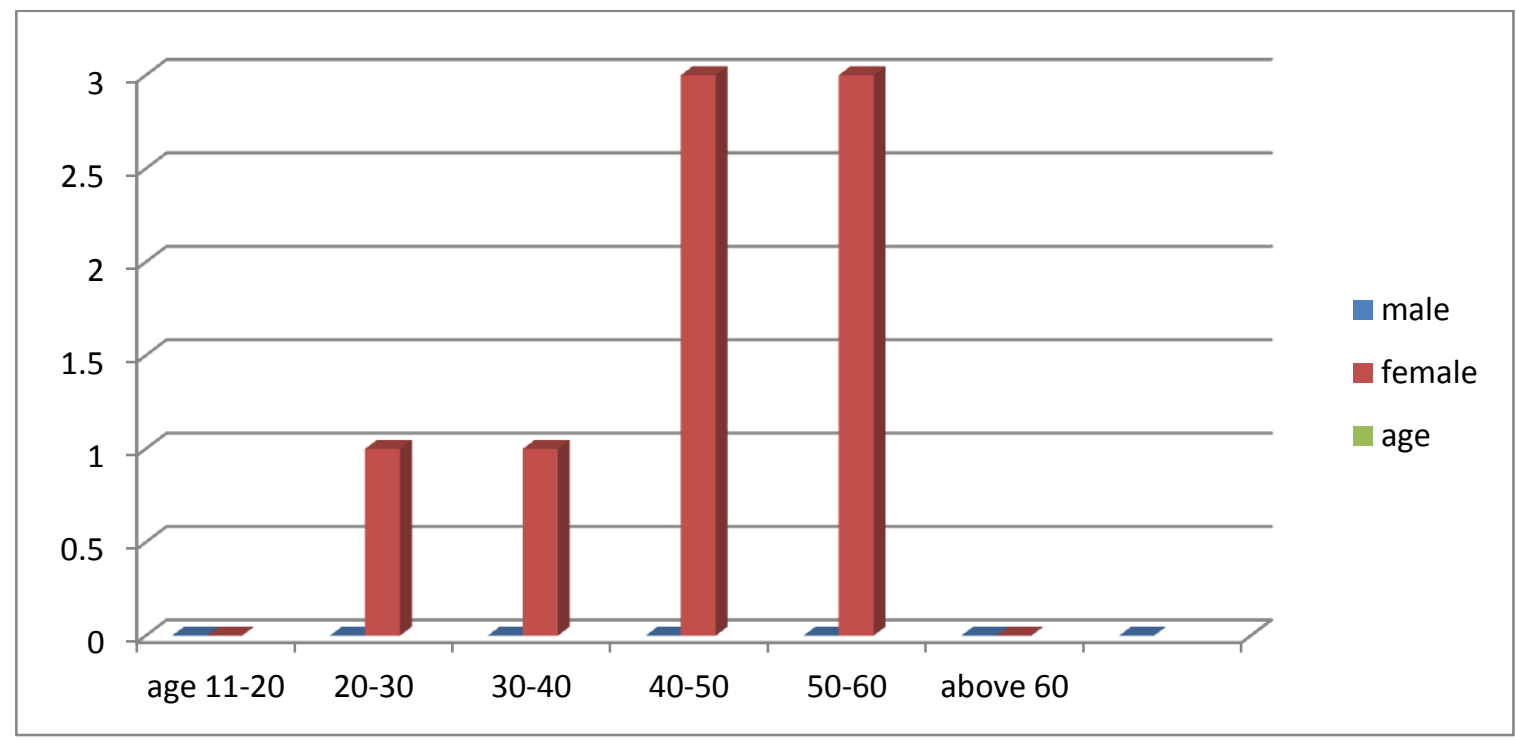

Age and sex distribution of the patients with HASHIMOTOS

$\begin{array}{crcl}\text { Age group (years) } & \text { Male } & \text { Female } & \text { Total } \\ 11-20 & 0 & 0 & 00 \\ 21-30 & 0 & 2 & 02 \\ 31-40 & 0 & 4 & 04 \\ 41-50 & 0 & 5 & 05 \\ 51-60 & 0 & 3 & 03 \\ >60 & 0 & 1 & 01\end{array}$

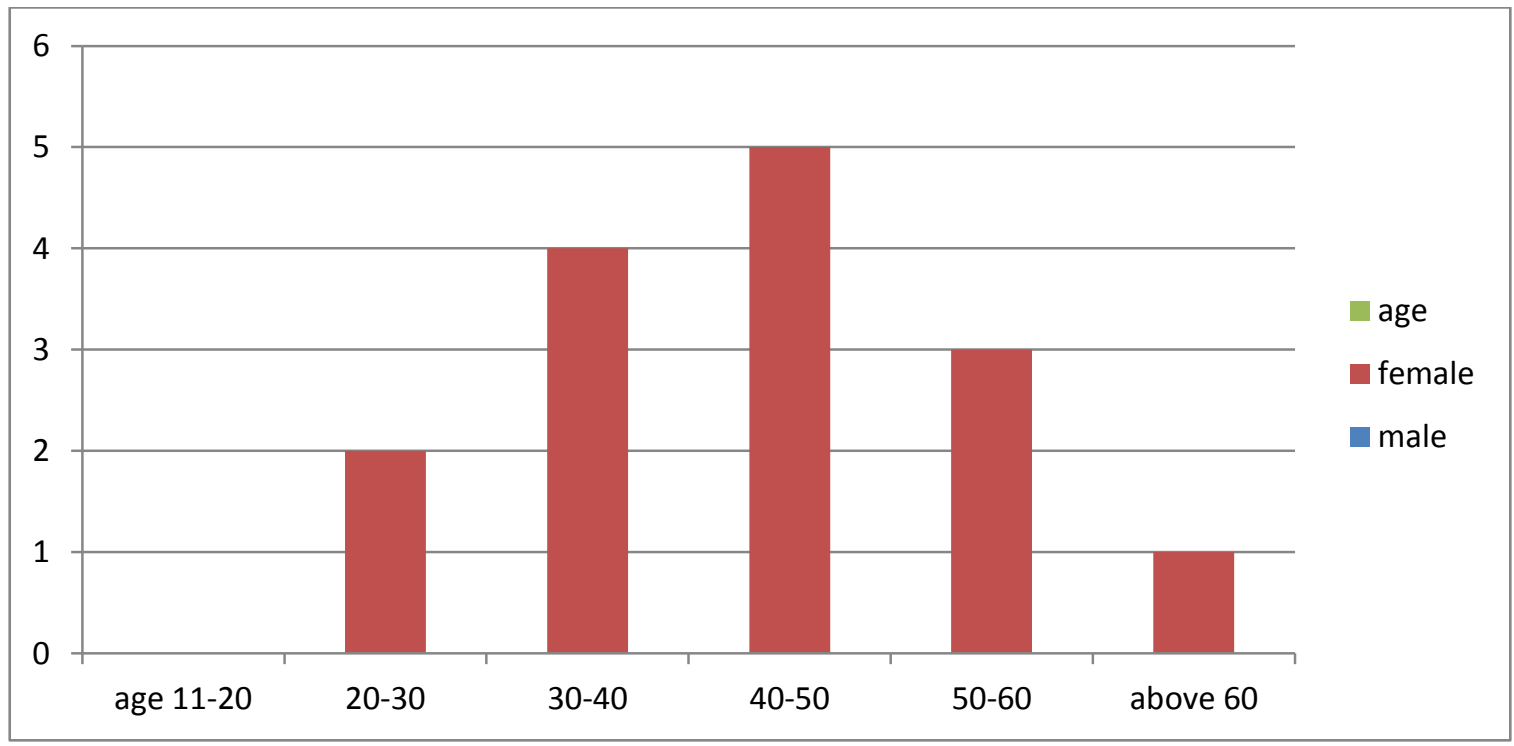




\section{JMSCR Vol||05||Issue||02||Pages 17425-17431||February}

Age and sex distribution of the patients with PAPILLARY CARCINOMA

$\begin{array}{cccc}\text { Age group (years) } & \text { Male } & \text { Female } & \text { Tota } \\ 11-20 & 0 & 0 & 00 \\ 21-30 & 0 & 1 & 01 \\ 31-40 & 0 & 6 & 06 \\ 41-50 & 1 & 3 & 04 \\ 51-60 & 0 & 0 & 00 \\ >60 & 0 & 0 & 00\end{array}$

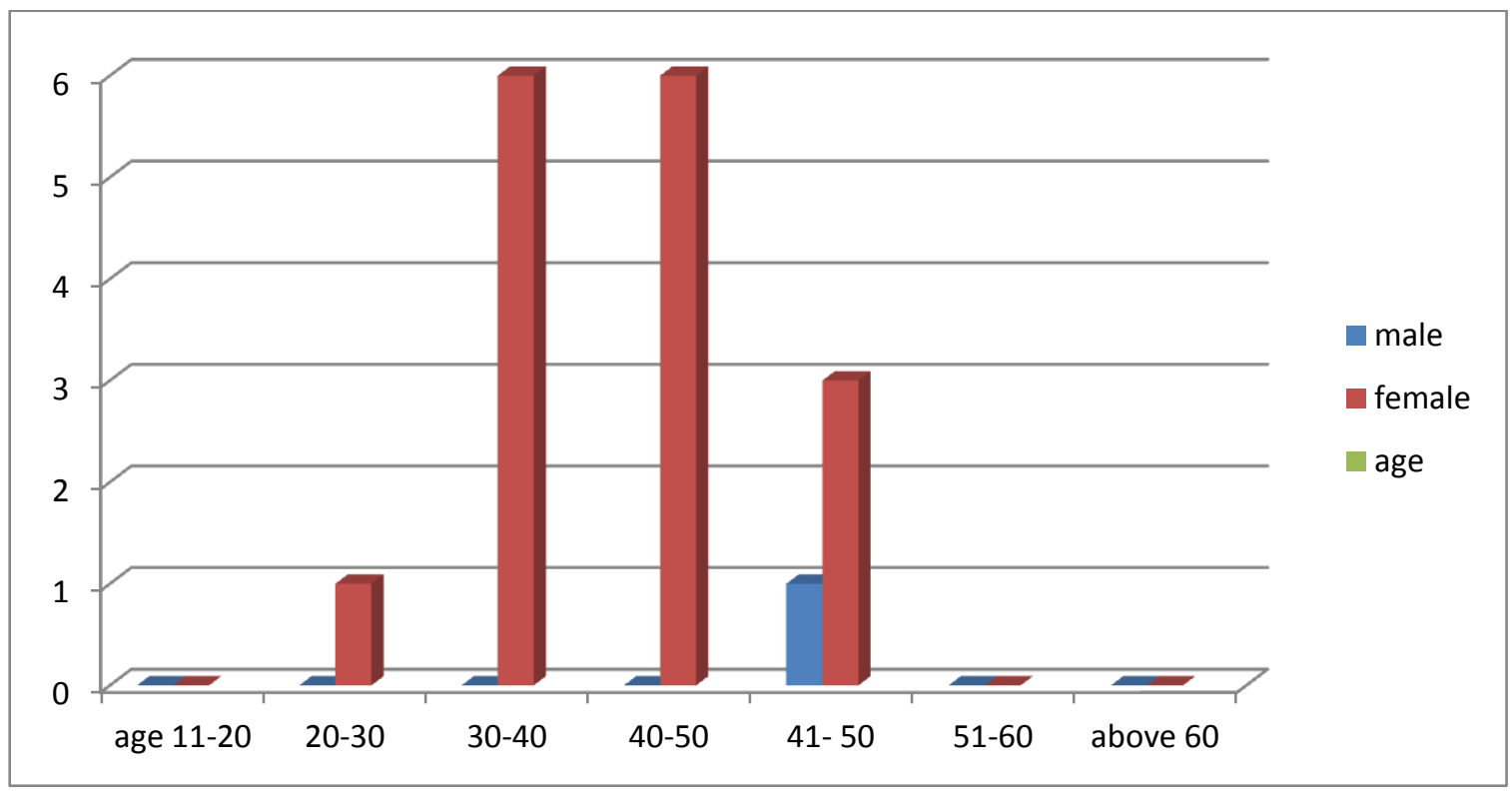

Age and sex distribution of the patients with MEDULLARY CARCINOMA.

$\begin{array}{cccc}\text { Age group (years) } & \text { Male } & \text { Female } & \text { Total } \\ 41-50 & 1 & 0 & 01 \\ 51-60 & 0 & 1 & 01\end{array}$

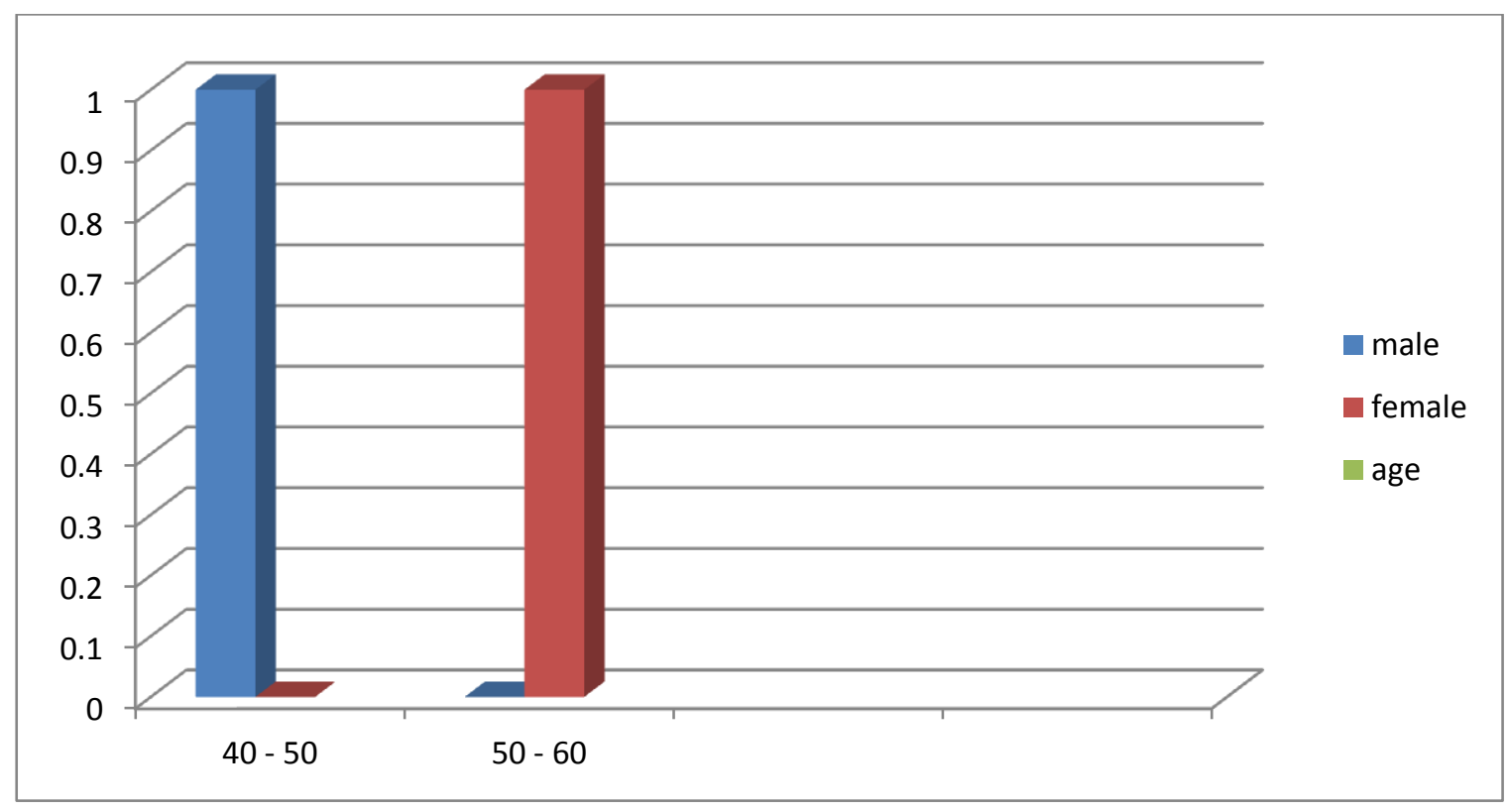




\section{Discussion}

In the present study, most of the patients are females (96\%) with 21-50 years age patients affected more commonly (63\%). Out of 100 cases histopathology was available in all cases and correlated with cytological diagnosis. In the present study, out of 100 cases, benign lesions were $77 \%$, malignant lesions were $13 \%$ and $10 \%$ were suspicious lesions.
In the study done by Chandanwale et $\mathrm{al}^{2}$, malignant lesions were $4 \%$ out of which $2.6 \%$ were papillary carcinoma. In the study done by Moosa et $\mathrm{al}^{6}$, malignant lesions were $7.9 \%$ out of which $6.8 \%$ were papillary carcinoma. In the present study, benign lesions constituted 68\%, malignant lesions $14 \%$ out of which papillary carcinoma were $11 \%$ of cases.

Distribution of various cytological lesions in different series

\begin{tabular}{|l|c|c|c|}
\hline & $\begin{array}{c}\text { Chandanwale et al. } \\
150 \text { cases. }\end{array}$ & $\begin{array}{c}\text { Moosa et al. } \\
98 \text { cases. }\end{array}$ & $\begin{array}{c}\text { Present study. } \\
100 \text { cases. }\end{array}$ \\
\hline Benign lesions. & $77.6 \%$ & $89.8 \%$ & $77 \%$ \\
\hline Malignant lesions & $6.75 \%$ & $8.16 \%$ & $13 \%$ \\
\hline Suspicious & $13.65 \%$ & $2.04 \%$ & $10 \%$ \\
\hline
\end{tabular}

Distribution of results:

\begin{tabular}{|l|c|c|c|}
\hline STUDY & Chandanwale et al. & Moosa et al & Present study \\
\hline Sensitivity & $90 \%$ & $77.7 \%$ & $85 \%$ \\
\hline Specificity & $100 \%$ & $98.9 \%$ & $100 \%$ \\
\hline
\end{tabular}

In our series detailed history was taken and clinical evaluation was done for every cases. All the 100 patients presented to us with a complain of swelling at thyroid region. Most of the patients were asymptomatic at the time of presentation. Other presenting features were matatastatic cervical lymphadenopathy five $(5.55 \%)$ out of 100 cases, two $(2.22 \%)$ presented with dyspnoea (due to pressure by huge thyroid swelling) and two $(2.22 \%)$ presented with change of voice (due to right vocal cord palsy). Regarding the duration of thyroid swelling, maximum thirty four $(37.78 \%)$ out of 100 presented to us in our series with the duration of 1-2 years. Shortest duration of thyroid swelling was 8 months and longest duration was 12 years.

In general, Palpable thyroid nodules are present in approximately $4-7 \%$ of adults ${ }^{3,4}$ and are more common in females with a Female: Male ratio of $4.2: 1^{(5)}$. In the present study also there was a female predominance. The lesions were common in females with the male: female ratio being 1: 24 and the mean age of the patients was 40.14 years.
Thyroid gland carcinoma accounts for less than $1 \%$ of all cancers and is responsible for $0.5 \%$ of all cancer-related deaths ${ }^{10}$. Early diagnosis of such cases is thus important for aiming at higher life expectancy especially since thyroid gland cancers have a low malignant potential and also have a slow progressive property. Majority of the clinically diagnosed palpable thyroid nodules are non-neoplastic. Multiple aspirations avoid missing a neoplastic focus. Every thyroid FNAC should be evaluated for adequacy of the smears. FNAC used together with other diagnostic modalities such as thyroid scanning, ultrasonography, thyroid hormone and antibody level measurements enhances the diagnostic accuracy of the technique. All the patients, tolerated the aspiration procedure and there were no complications. Among the nonneoplastic lesions, Benign follicular lesion (8\%) and colloid goitre was commonly encountered (53\%). Hashimoto's thyroiditis was diagnosed in 13 cases out of 15 cases. 


\section{JMSCR Vol||05||Issue||02||Pages 17425-17431||February}

\section{Limitations}

The major limitation of FNAC is its insensitivity in correctly diagnosing malignant follicular lesions. In addition; a proportion of cases cannot be evaluated because of paucity of material ${ }^{8}$.

\section{Conclusions}

FNAC exhibits an adequate diagnostic correlation with the final histopathological examination and enables a comparison of results between different institutions. Our results are consistent with those available in the literature. FNAC is an invaluable tool in the management of thyroid lesions with a high degree of accuracy. It is safe, simple, costeffective procedure with absence of major complications and can be performed on outpatients with wide patient compliance. FNAC provides a more rapid and accurate diagnosis of thyroid lesions than any other combination of clinical laboratory tests. But, Histopathology is always required to confirm the diagnosis and for further management.

\section{Reference}

1. Baloch ZW, LiVolsi VA, Asa SL, et al. Diagnostic terminology and morphologic criteria for cytologic diagnosis of thyroid lesions: a synopsis of the National Cancer Institute Thyroid Fine-Needle Aspiration State of the Science Conference. Diagn Cytopathol. 2008; 36:425-37.

2. Chandanwale S, Singh N, Kumar H, Pradhan P, Gore C, Rajpal M. Clinicopathological correlation of thyroid nodules.Int $\mathbf{J}$ Pharm Biomed Sci 2012;3(3):97-102.

3. Gita J, Orell SR. Thyroid. In: Orell SR, Sterrett GF, editors. Fine Needle Aspiration Cytology. 5th ed. Philadelphia: Churchill Livingstone; 2012.118-55.

4. Gharib H, Goellner JR. Fine needle aspiration biopsy of the thyroid:an appraisal. Ann Intern Med 1993;118:282-9 3.

5. Gupta M, Gupta S, Gupta VB.Correlation of fine needle aspiration cytology with histopathology in the diagnosis of solitary thyroid nodule. J Thyroid Res 2010; 10:15. PMCID: PMC2956979

6. Foad Ali Moosa et al: Upto what extent FNAC is accurate in detecting malignancy in solitary thyroid nodule? (A comparison with post-operative histopathology findings). Medical Channel 2010;16(2)

7. Handa U, Garg S, Mohan H (2008) Role of fine needle aspiration cytology in diagnosis and management of thyroid lesion. Indian J Pediatr 25(1):13-17

8. Svante R Orell. Manual and Atlas of Fine Needle Aspiration Cytology, 2012; 6: 118149.

9. Razmpa E. et al: Comparison of ultrasound findings with cytological result in thyroid nodules. Acta Medica Iranica, 2002; 40: 3.

10. Roman SA. Endocrine tumors: Evaluation of the thyroid nodule. CurrOpinOncol 2003; 15:66-70. 